\title{
Facilitators and barriers in anorexia nervosa treatment initiation (FABIANA): study protocol for a mixed-methods and multicentre study
}

Denise Kästner, Ines Buchholz, Angelika Weigel, Romuald Brunner, Ulrich Voderholzer, Antje Gumz* and Bernd Löwe*

\section{Background}

Anorexia nervosa is a serious disorder, which often takes a chronic course. Early treatment leads to a significantly better prognosis and prevents chronicity. However, existing evidence on facilitators and barriers in anorexia nervosa treatment initiation is scarce.

\begin{abstract}
Aims
Against this background, the FABIANA study (ClinicalTrials.gov Identifier: NCT03713541) aims to (a) identify potentially modifiable facilitators and barriers from the perspectives of adolescent and adult patients with anorexia nervosa, carers and physicians, (b) develop and test an instrument for the combined assessment of multiple key facilitators and barriers, and (c) quantify the effect of potentially modifiable versus non-modifiable key facilitators and barriers on the duration of untreated illness (DUI) in patients with anorexia nervosa.
\end{abstract}

\section{Method}

FABIANA is an observational, mixed-method-study divided into three consecutive substudies each corresponding to one of the study aims. All three substudies will include female patients with anorexia nervosa aged 14 years and older at the beginning of their first psychotherapeutic anorexia nervosa treatment. The qualitative substudy I and the quantitative substudy III will additionally include carers and involved physicians. The recruitment will take place at 20 cooperating study centres throughout Germany, which provide in-patient or out-patient anorexia nervosa specialist care. The DUI will be calculated based on the month of illness onset as determined in validated interviews on lifetime anorexia nervosa symptoms and the therapist-reported date of treatment initiation.

\section{Conclusions}

Strengths and limitations of the retrospective assessment of the DUI will be discussed. The findings of the FABIANA study will contribute to the development of evidence-based early-intervention approaches and the prevention of a chronic course of illness.

\section{Trial registration}

ClinicalTrials.gov Identifier: NCT03713541.

\section{Declaration of interest}

None.

\section{Keywords}

Anorexia nervosa; duration of untreated illness; early intervention; facilitators and barriers; psychotherapy.

\section{Copyright and usage}

(C) The Author(s) 2019. This is an Open Access article, distributed under the terms of the Creative Commons AttributionNonCommercial-NoDerivatives licence (http://creativecommons.org/licenses/by-nc-nd/4.0/), which permits non-commercial re-use, distribution, and reproduction in any medium, provided the original work is unaltered and is properly cited. The written permission of Cambridge University Press must be obtained for commercial re-use or in order to create a derivative work

\section{Background}

Anorexia nervosa is an eating disorder mainly characterised by selfinduced underweight, intense fear of weight gain and body image distortions. ${ }^{1}$ Anorexia nervosa predominantly affects female patients, has its onset during adolescence or young adulthood and the estimated lifetime prevalence among female patients ranges between 1 to $4 \%{ }^{2,3}$ The disorder is associated with severe individual and societal burden. The high mortality rates in individuals with anorexia nervosa are repeatedly emphasised and exceed the rates of any other mental disorder. ${ }^{4,5}$ Even when non-lethal, the somatic symptoms because of underweight are various and concern neurobiological, cardiac, endocrine and skeletal alterations. ${ }^{6}$ Furthermore, individuals with anorexia nervosa commonly have psychiatric comorbidities and a decreased quality of life., From a societal perspective, anorexia nervosa was found to generate direct healthcare costs comparable with schizophrenia. ${ }^{8}$

In general, specialised treatment has proved effective, with respect to the improvement of eating disorder-related symptoms as well as secondary outcomes such as depression or quality of life. ${ }^{6}$ Psychotherapy should be central in the treatment of anorexia

* These authors share last authorship. nervosa. In adolescent patients, family therapeutic approaches are regarded as first-line treatment. In adult patients, different psychotherapeutic approaches proved equally effective and can be considered evidence based and guideline recommended. ${ }^{9}$ Despite the general effectiveness of psychotherapy, the course after treatment is highly variable. Relapses are common ${ }^{10}$ and long-term studies suggest that even 20 years after treatment only $40 \%$ to $50 \%$ achieve remission. ${ }^{11}$

\section{Duration of untreated illness}

Strong indications point to the conclusion that an early diagnosis and treatment leads to a significantly better prognosis and might be decisive in the prevention of a chronic course of illness. ${ }^{12,13}$ This may not be surprising since the time interval between the illness onset and the beginning of the first specialist treatment (i.e. duration of untreated illness, DUI) is a well-established factor influencing the outcome in several mental disorders. ${ }^{14}$ Accordingly, this area of research, which is associated with varying terminology (such as early intervention, delays to treatment, pathways to care, DUI), has received increasing attention over the years. ${ }^{15}$ However, for individuals with anorexia nervosa, the evidence is still tremendously scarce. For example, a recent review 
on pathways to care included 32 studies on people at risk for psychosis or with first-episode psychosis and only one study on individuals with anorexia nervosa. ${ }^{16}$

The few existing studies have demonstrated an average DUI in anorexia nervosa of nearly 3 years despite the visibility of the disorder and a well-developed mental healthcare system in Germany. ${ }^{17}$ Furthermore, they found that the most common first contacts on the way to the initial treatment were general practitioners and family or friends. ${ }^{16,18}$ Current knowledge on the factors influencing DUI (i.e. facilitators and barriers in treatment initiation) in individuals with anorexia nervosa is limited and highly heterogeneous in design and sampling as well as the control for potentially confounding variables. ${ }^{19,20}$ However, this knowledge would be an important starting point for the development and prioritisation of early intervention approaches.

Two recent reviews summarised the lack of research on facilitators and barriers in treatment initiation in detail. First, most evidence refers to all eating disorders rather than specially focusing on anorexia nervosa. ${ }^{20}$ However, anorexia nervosa-specific mechanisms in the process of treatment initiation may be likely, for example because of the visibility of the illness in most cases. ${ }^{21}$ Second, the vast majority of existing studies exclusively investigated adult patients. ${ }^{19}$ However, it seems probable that different facilitators and barriers in treatment initiation apply to adolescent patients. ${ }^{19}$ Third, despite the previously mentioned role of general practitioners and carers in diagnosing and treatment-seeking, to the best of our knowledge there is no single study considering their perspectives. ${ }^{19,20}$ Fourth, individual facilitators and barriers most likely differ regarding their potential modifiability (i.e. the possibility of exerting influence on them). Yet, a systematic distinction cannot be found in the literature so far. ${ }^{20}$ Fifth, an instrument to assess multiple facilitators and barriers in a reliable and valid way may be important to strengthen the evidence base, but is currently missing. ${ }^{19,22}$ Finally, conclusions regarding the facilitators and barriers with the best predictive utility can currently not be made. ${ }^{20}$

\section{Study aims}

Against this background, the FABIANA study (ClinicalTrials.gov Identifier: NCT03713541) has the following aims.

(a) Explore patterns, thoughts and behaviours involved in the process of treatment initiation in order to identify potentially modifiable facilitators and barriers from the perspectives of adolescent and adult patients with anorexia nervosa, carers and physicians

(b) Develop and test an instrument for the combined assessment of multiple key facilitators and barriers in anorexia nervosa treatment initiation.

(c) Quantify the influence of potentially modifiable key facilitators and barriers versus non-modifiable factors (for example age, migration status, eating disorder pathology) on the DUI.

In conclusion, we aim to derive evidence-based recommendations for improved early-intervention approaches in anorexia nervosa in order to be able to treat more patients at early stages of their illness in the future.

\section{Method}

\section{Study design}

The FABIANA study is divided into the three consecutive substudies I-III corresponding to the outlined study aims. An overview of the FABIANA substudies including the planned recruitment phases is provided in Fig. 1. All substudies use an observational, cross-sectional, retrospective, multicentre design. The qualitative substudy I and the quantitative substudy III are multi-informant studies and aim to include triads of patients with anorexia nervosa, carers and physicians. A detailed description of the substudies follows below.

\section{Study centres}

The main study centre of the FABIANA study is located at the Institute for Psychosomatic Medicine and Psychotherapy of the University Medical Center Hamburg-Eppendorf, Germany. Additionally, 20 cooperating partners are involved in the recruitment of eligible patients. The exact locations of the cooperating study centres are shown in Fig. 2. The cooperating study centres consist of 12 in-patient clinics, 2 medical care centres, 2 psychotherapy training centres, several psychotherapists providing out-patient care, and 1 counselling centre. Three of the in-patient clinics, one of the medical care centres and all remaining out-patient care providers are located in Hamburg. The remaining cooperating centres are located throughout Germany. During the course of the study additional out-patient care providers might be recruited. As specified in Fig. 2 only selected study centres will participate in substudy I, whereas all study centres will be involved in substudy II and substudy III.

All cooperating study centres provide and/or refer into specialised eating disorder treatment in the context of routine care provision in Germany. This means for all settings that psychotherapy is the integral part of the treatment. All in-patient and day-patient care providers offer multimodal treatments consisting of individual psychotherapy, group psychotherapy, nutritional therapy including weight contracts, psychoeducation and different non-verbal therapies. Outpatient treatment is either cognitive-behavioural or psychodynamic individual psychotherapy. For adolescents, family therapeutic sessions are usually added in both settings. The intensity of out-patient treatment usually ranges from 24 to 100 sessions. All cooperating study centres have experience of several years in the treatment of patients with eating disorders. The costs of out-patient and in-patient psychotherapeutic treatments are fully covered by all statutory health insurances in Germany. Individually specific reimbursement regulations apply for individuals who have private health insurance (approximately $9 \%$ of all insured people). ${ }^{23}$

\section{Eligibility and recruitment}

The inclusion and exclusion criteria, that apply to all substudies equally, are presented in Table 1 . The rationale for the criteria in detail is as follows: the minimum age limit of 14 years was chosen in light of the sufficiently consolidated development of higherorder cognitive functions (such as abstract, logical thinking and reasoning, the ability to reflect on oneself or complex problem-solving) at the end of early adolescence. ${ }^{24}$ This criterion seems especially important for the participation in the qualitative interviews in substudy I. Additionally, the chosen age limit allows for greater consistency within the applied instruments (in particular Structured Clinical Interview for DSM-IV Axis I/II diagnoses (SCID) assessments $^{25,26}$ ).

In addition, we specified criteria regarding the timing of the first psychotherapeutic treatment. Accordingly, the treatment commencement should not be longer than 3 months previously, in order to minimise the risk of recall biases and response shifts. ${ }^{27}$ However, patients should also not be included in the study at the very beginning of their treatment (i.e. before the completion of 7 days as an in-patient or five sessions of out-patient treatment) in order to exclude patients on a waiting list or individuals with early treatment drop-out. In line with this reasoning, earlier psychotherapeutic treatments only constitute as such, if they lasted for or 


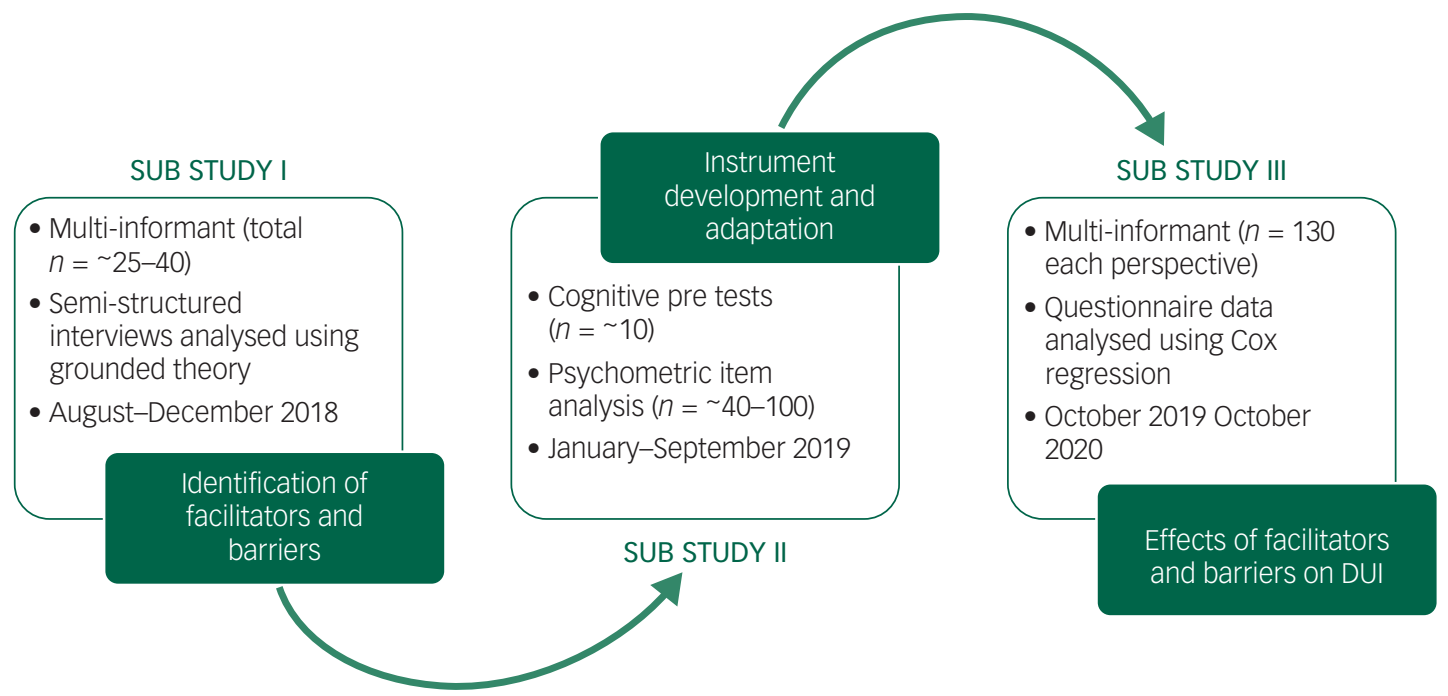

Fig. 1 Overview of the FABIANA substudies.

DUI, duration of untreated illness.

exceeded this duration (7 days inpatient treatment or five sessions outpatient psychotherapy).

Eligible study participants need to fulfil all inclusion criteria and no exclusion criteria. In the first step, the cooperating partners will screen for eligible patients in the context of their regular admission interviews or initial consultations. They will inform eligible patients about the study, invite study participation and hand out study materials (i.e. written informed consent, questionnaires). Afterwards, the study team examines the final eligibility of each patient in the context of an interview for example validation of anorexia nervosa diagnosis using SCID-I, fulfilment of the specified criteria regarding first psychotherapeutic treatment).

The recruitment of carers and involved physicians is based on the included patients. Therefore, study patients will be asked to name one carer, who supported or followed their path from illness onset to treatment initiation, and one physician, who was involved in the process of treatment initiation (for example diagnosis, referral). After obtaining the patient's written consent to contact the carer or the release of patient-doctor confidentiality the study team will invite the carer or physician to participate in the study.

\section{Assessment of DUI}

DUI will be assessed in all participating patients throughout all substudies and will be specified in months. The DUI is operationalised as the time interval between the anorexia nervosa illness onset and the beginning of a psychotherapeutic anorexia nervosa treatment.

The retrospective assessment of the illness onset is based on a combination of questionnaire data and SCID-I lifetime interview. ${ }^{26}$ The two-staged procedure follows existing recommendations to minimise recall biases ${ }^{28}$ and was tested within a small pilot study ( $n=14: n=3$ adolescent patients, $n=11$ adult patients). First, the patient answers questionnaire items on the lowest and highest weight, episodes of rapid weight loss and the lifetime occurrence of different anorexia nervosa symptoms (for example amenorrhea, binge eating). Afterwards, the patient is asked to map each item on a life chart. The life chart is constructed to shortly describe important life events or stages of life as anchor points in the free space below the timeline and the first occurrence of single anorexia nervosa symptoms in the space above the timeline. This questionnaire data is used as preparation for the SCID-I anorexia nervosa lifetime interview, which is used to finally determine the month of illness onset. As recommended, the assessment will focus especially on the onset of somatic and behavioural symptoms (such as first occurrence of underweight, amenorrhea, beginning of purging behaviours) rather than on psychological symptoms (such as body image disturbance, fear of weight gain). ${ }^{28}$

The beginning of the first psychotherapeutic anorexia nervosa treatment is either the date of hospital admission or the date of the first out-patient psychotherapy session. It will be assessed using a short questionnaire, which is filled out by the treating psychotherapist. In case of a missing therapist report, the patientreported date will be used as a surrogate.

\section{Substudy I}

The main aim of the qualitative substudy I is to identify facilitators and barriers in anorexia nervosa treatment initiation from the perspectives of patients, carers and involved physicians using personal interviews. For sample description purposes, various other variables will be assessed. An overview of the complete data collection of substudy I is provided in the Appendix. Based on the therapist-reported weight and height, we will calculate the body mass index (BMI) as $\mathrm{kg} / \mathrm{m}^{2}$. In adolescent patients we will additionally calculate the age- and gender-adjusted BMI percentiles and the percentage of expected body weight (observed BMI/50th percentile BMI $\times 100$ ) using the latest representative growth charts for children and adolescents in Germany. ${ }^{29,30}$

The interviews on facilitators and barriers will be semi-structured using an interview guideline created for each perspective. The guidelines begin with open questions to reflect on personal experiences during the process from illness onset to treatment initiation, and get increasingly more problem-centred and focused on potentially modifiable facilitators and barriers. Each interview is expected to last 30 to $90 \mathrm{~min}$. The interviews with the patients will be face to face, and the interviews with carers and physicians will be conducted by phone. All interviews will be audio-taped and transcribed.

According to the applied grounded theory approach, a theoretical sampling method with the goal to include patients whose cases are heterogeneous (particularly with respect to DUI and age group) will be used. Therefore, the sampling procedure can be considered 
Sub study I+ II + III

O Sub study II + III

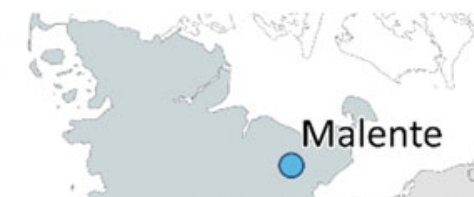

\section{Cuxhaven}

OBad Bramstedt

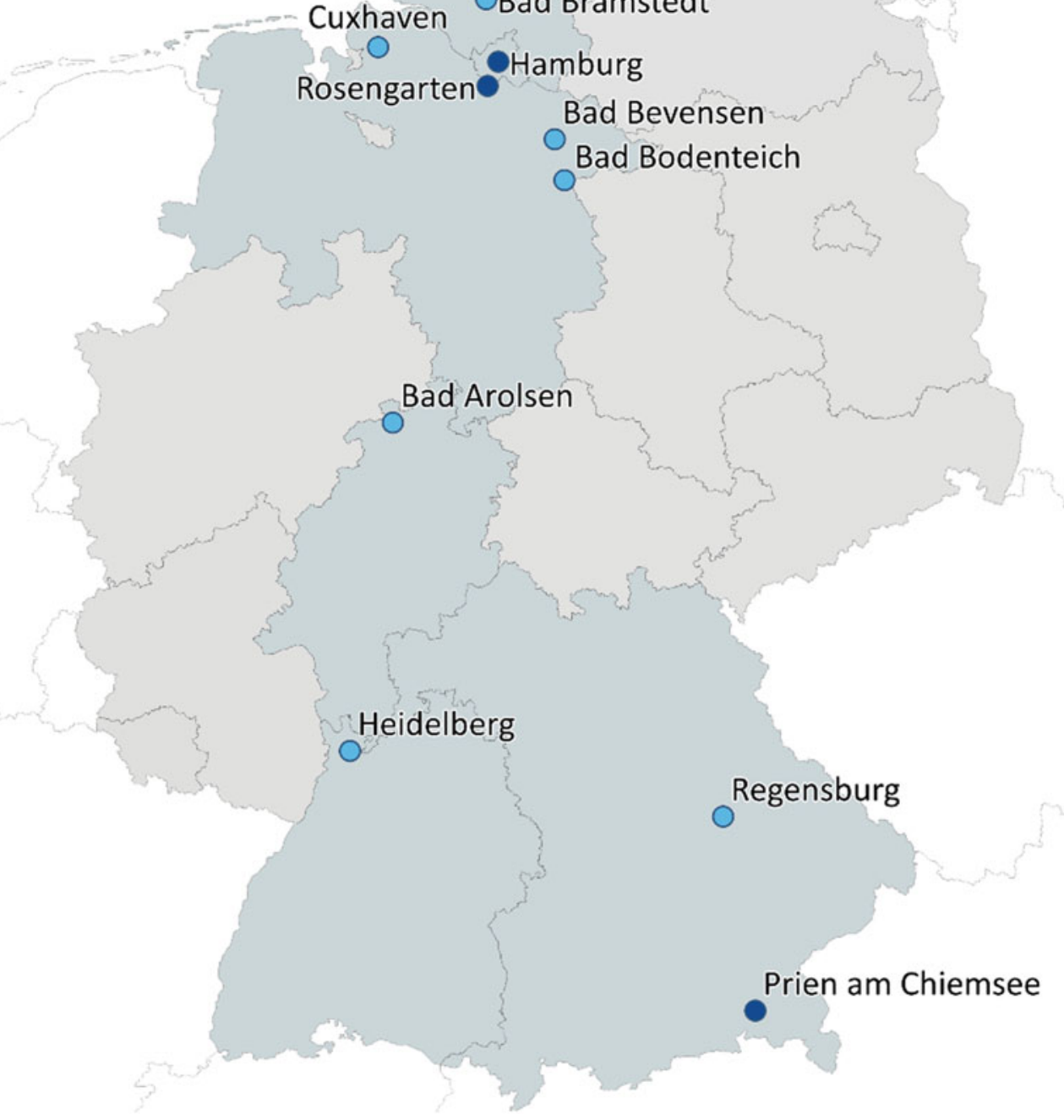

Fig. 2 Location of FABIANA study centres across Germany

\begin{tabular}{|c|c|c|c|}
\hline & Patients & Carers & Physicians \\
\hline $\begin{array}{l}\text { Inclusion } \\
\text { criteria }\end{array}$ & $\begin{array}{l}\text { Female gender } \\
\geq 14 \text { years } \\
\text { Diagnosis anorexia nervosa (Structured Clinical Interview for DSM- } \\
\text { IV diagnoses) } \\
\text { First psychotherapeutic anorexia nervosa treatment, i.e.: (a) the } \\
\quad \text { start no longer than } 3 \text { months ago; (b) at least } 7 \text { days of in- } \\
\text { patient care or five sessions out-patient care completed; (c) } \\
\text { since illness onset no psychotherapeutic anorexia nervosa } \\
\text { treatment (of at least } 7 \text { days in-patient or five sessions out- } \\
\text { patient therapy) }\end{array}$ & $\begin{array}{l}\text { In patients aged } 14-15 \text { years: } \\
\text { parent } \\
\text { In patients aged } \geq 16 \text { years: any } \\
\text { significant other (for example } \\
\text { relative, partner, friend) } \\
\text { Patient named the person and } \\
\text { gave consent }\end{array}$ & $\begin{array}{l}\text { At least one patient contact within the } \\
\text { past } 12 \text { months } \\
\text { Physician in private practice (for } \\
\text { example general practitioner, } \\
\text { paediatrician, gynaecologist) } \\
\text { Patient named the person and gave } \\
\text { release of confidentiality }\end{array}$ \\
\hline $\begin{array}{l}\text { Exclusion } \\
\text { criteria }\end{array}$ & $\begin{array}{l}\text { Insufficient language skills } \\
\text { Acute suicidality } \\
\text { Serious comorbid psychiatric disorder (for example psychotic } \\
\quad \text { symptoms) } \\
\text { Serious comorbid somatic disorder that would prohibit study } \\
\quad \text { participation }\end{array}$ & Insufficient language skills & Insufficient language skills \\
\hline
\end{tabular}




\begin{tabular}{|c|c|c|c|}
\hline Covariate & Operationalisation & Hypothesis & References \\
\hline \multicolumn{4}{|l|}{ Predisposing factors } \\
\hline Age & Basic information questionnaire: in years & - & $18,20,41$ \\
\hline Migrant background & $\begin{array}{l}\text { Basic information questionnaire: yes (own) } \\
\quad \text { versus yes (parents) versus no }\end{array}$ & $\begin{array}{l}\text { Non-migrant background is associated with a shorter DUI than } \\
\text { migrant background }\end{array}$ & $17,20,40$ \\
\hline \multicolumn{4}{|l|}{ Enabling factors } \\
\hline Insurance & $\begin{array}{l}\text { Basic information questionnaire: statutory } \\
\text { versus private }\end{array}$ & $\begin{array}{l}\text { Private health insurance is associated with a shorter DUI than } \\
\text { statutory health insurance }\end{array}$ & 17,40 \\
\hline \multicolumn{4}{|l|}{ Need factors } \\
\hline Comorbidity & $\begin{array}{l}\text { SCID-I/II interview: number of comorbid } \\
\text { diagnoses }\end{array}$ & - & 20 \\
\hline BMI at treatment initiation & Therapist report & Higher BMI is associated with shorter DUI than lower BMI & 17 \\
\hline Anorexia nervosa subtype & SCID-I interview & $\begin{array}{l}\text { The restrictive anorexia nervosa subtype is associated with a } \\
\text { shorter DUI than the binge purge anorexia nervosa subtype }\end{array}$ & 20 \\
\hline Eating disorder pathology & Short version EDE-Q or ChEDE-Q & $\begin{array}{l}\text { Less severe eating disorder pathology is associated with a } \\
\text { shorter DUI than more severe eating disorder pathology }\end{array}$ & 20 \\
\hline
\end{tabular}

as an iterative process that will be finished with theoretical saturation. ${ }^{31,32}$ A total number of 25 to 40 interviews is expected (i.e. 10 to 15 triads of patients, carers and physicians including nonresponse). Each interview will be analysed independently by two members of the study team using grounded theory as the theoretical approach and MAXQDA as analysis software. ${ }^{33}$ Grounded theory distinguishes three modes of coding the interview material (open, axial and selective coding). The identification of key facilitators and barriers will be a result of the selective coding, for which we apply established criteria as representativeness (i.e. quantity of material implying the relevance of a factor) and interconnectedness (i.e. relevance for other factors). ${ }^{34}$

\section{Substudy II}

The key factors identified in substudy I form the basis to subsequently develop an instrument for the combined assessment of multiple facilitators and barriers in anorexia nervosa treatment initiation, which is the main aim of substudy II.

As recommended, anchor examples (i.e. prototypical statements) from the qualitative interviews will be inspected regarding their use for item formulation. ${ }^{35}$ The feasibility of this newly constructed instrument will be tested using cognitive interviews in a sample of ten patients with anorexia nervosa. The cognitive protests aim to detect items that may not be sufficiently easy to understand, clear or recallable. These items will be re-formulated.

Afterwards, the first comprehensive psychometric test of the instrument will be conducted in 40 to 100 patients using principal component analysis. The sample size is based on the recommendation to include at least four participants for each item in order to carry out the planned principal component analysis. ${ }^{36}$ Patients will be recruited consecutively in all cooperating study clinics during a time period of 4-5 months. Study patients will be asked to fill out the newly developed instrument as well as the basic information questionnaire from substudy I (Appendix, excluding SCIDII). Moreover, established measures (such as on treatment motivation, perceived stigma) will be applied to validate the instrument depending on the identified key factors. Finally, the instrument will be adapted based on the results of the psychometric item analysis (for example the parameters mean, standard deviation, range, skewness, kurtosis, item-total correlation, Cronbach's alpha) and the principal component analysis. ${ }^{37}$

\section{Substudy III}

In order to finally derive recommendations and prioritise earlyintervention approaches, it is essential to quantify the effect of individual facilitators and barriers on the DUI. This is the major aim of substudy III.

Apart from the qualitative interviews, data collection is analogous to substudy I but supplemented by the newly developed instrument to assess facilitators and barriers in treatment initiation, and the German eight-item short version of the Eating Disorder Examination - Questionnaire (EDE-Q) or Child EDE-Q (ChEDE-Q) depending on the age group. ${ }^{38,39}$ The application of further questionnaires will be influenced by the results of substudy I and II.

In the prediction of DUI, we will control for fixed, non-modifiable variables with a potential influence (Table 2). The non-modifiable control variables were $a$ priori selected based on the existing evidence. Specifically, we included all non-modifiable variables that demonstrated a significant influence on the DUI or the treatment initiation in at least two eating disorder studies or one anorexia nervosa study. The variables were theoretically grouped into predisposing, enabling and need factors according to Andersen's behavioural model of health service use. ${ }^{40}$ Strong evidence exists for some of the prespecified covariates (i.e. migration background, purging behaviour as operationalised via the anorexia nervosa subtype), whereas the influence of other covariates is only supported by single studies (i.e. insurance status, BMI, eating disorder pathology). Conflicting evidence exists regarding the role of age and comorbidity with some indications of higher age and comorbidity in treatment seekers and other findings that imply the opposite direction. ${ }^{20}$ Consequently, no directed hypothesis was formulated. In general, it is expected that a significant amount of variance will already be explained by the prespecified covariates.

Prior to the prediction, a non-responder analysis including age as independent variable will be conducted. Furthermore, the missing data mechanism (missing completely at random, missing at random or not missing at random) will be analysed and an imputation model depending on the existing mechanism will be selected. Intercorrelations of predictor variables will be examined, and highly intercorrelated variables may be excluded. Finally, a Cox regression model will be computed including the prespecified control variables, the cluster variable 'setting' (in-patient versus out-patient), and the key facilitators and barriers as potential predictors of the DUI in anorexia nervosa. The Cox regression model was chosen, because the DUI is a usually heavily skewed, exponentially distributed time-to-event variable. ${ }^{14}$

For sample size calculation, we performed a simulation based on the assumptions of an exponentially distributed DUI with an intercept of $\log ^{31}$ (i.e. mean DUI of 31 months) ${ }^{17}$ and six uncorrelated predictors with a moderate effect $(\beta=\log (1.3))$. In order to reach a power of $80 \%, n=130$ study patients need to be included. 
Assuming a non-response rate of $25 \%, n=173$ patients need to be initially approached in substudy III.

\section{Ethics and dissemination}

Written informed consent will be obtained from all study participants prior to study inclusion. In minor participants, the consent of all legal guardians, or the consent of at least one legal guardian and written explanation regarding any missing consents are additionally required. Carers of study patients will be invited for study participation only after obtaining the patient's written consent to contact the respective carer. Along the same lines, physicians will only be contacted if the patient has signed a release from medical confidentiality. The physicians will receive a copy of this confidentiality release. The data will be handled confidentially. Reciprocal information between participants of individual triads is not intended. After study participation, all study participants will receive a financial compensation.

The authors assert that all procedures contributing to the FABIANA study will comply with the ethical standards of the relevant national and institutional committees on human experimentation and with the Helsinki Declaration of 1975, as revised in 2013. Ethical approval was obtained from the Ethic Committee of the Medical Association Hamburg (PV5108) on 11 November 2015. An amendment including an update of the study materials to comply with the European Union general data protection regulation was approved on 18 July 2018 . Secondary votes were obtained from the ethic committees of the medical associations in all relevant German federal states (i.e. Lower Saxony, Hesse, BadenWurttemberg and Schleswig-Holstein; the primary vote is generally accepted in Bavaria). The substudies will be conducted and reported in accordance with relevant reporting guidelines. ${ }^{42-44}$

\section{Results}

The results of the FABIANA substudies will be presented at national and international conferences, and published in peer-reviewed journals.

\section{Discussion}

The present study protocol describes a mixed-methods study that aims to broaden our understanding on facilitators and barriers in anorexia nervosa treatment initiation. Thereby, the three consecutive substudies systematically address previously outlined deficiences in the existing evidence on DUI and treatment initiation in anorexia nervosa. The findings of the FABIANA study may close crucial gaps in knowledge, which we will highlight in the following discussion alongside challenges and limitations associated with the study design.

\section{Knowledge gains and strengths of the study}

First of all, the results of the naturalistic, observational study will provide further descriptive information on the DUI in patients with anorexia nervosa under routine care conditions. This information will be of great value as there are few studies that have investigated the DUI in patients with anorexia nervosa and our data will be based on a relatively large sample from 20 study centres. The mean DUI as well as the percentage of patients with a comparably long DUI (DUI > 1 year) will provide information on the extent of problems with treatment delays in the current healthcare system and may be an important prerequisite to justify further investments in the development and implementation of innovative early-intervention approaches. ${ }^{45}$
In the exploration of potential facilitators and barriers, the FABIANA study aims to generate new insights, especially by the exclusive focus on patients with anorexia nervosa, the inclusion of adolescent patients, the application of a multi-informant approach, the continuous consideration of the modifiability and the quantitative analysis of the predictive utility of single factors. Currently, the evidence on treatment initiation is usually aggregated over patients with different eating disorders (for example Ali et al ${ }^{19}$ and Regan et $a l^{20}$ ). It can be assumed that certain transdiagnostic features (such as shame in patients with binge-purge behaviours) are relevant for the process of treatment initiation in different eating disorders. However, there may be specific characteristics for patients with anorexia nervosa, for example because of the visibility of the disorder. ${ }^{21}$ Another point critically noted regarding the sampling of existing studies is the underrepresentation of adolescent patients. ${ }^{19}$ Undoubtedly, it is essential to include younger patients, because the illness onset of anorexia nervosa is usually during adolescence. ${ }^{2}$ Furthermore, it seems highly likely that the factors influencing the process of treatment initiation differ depending on the age group as a result of the often decisive role of parents in adolescent patients. ${ }^{46}$ The findings of the FABIANA study may provide information on previously overlooked facilitators and barriers for adolescent patients with anorexia nervosa.

Moreover, to our knowledge, FABIANA is the first study, that incorporates the perspectives of carers and physicians on the process of anorexia nervosa treatment initiation. Carers are likely to have an important outside view on the complete process from first symptoms to treatment initiation. Information on possibilities and limits to support and on the needs of carers during this process should be considered. Physicians may have experience of and expert opinions on delays within the healthcare system, and both key contact people may provide valuable information not accessible from the patients. However, the triangulating design with the aim to collect data ideally from complete triads may also be challenging, especially since physicians response rates are known to be relatively low. ${ }^{47}$ In order to minimise non-response, frequent reminders, financial incentives and comprehensible and time-economic study materials will be used. ${ }^{47}$

A further strength of the FABIANA study is the consideration of the modifiability of identified facilitators and barriers, and the subsequent analysis of the predictive utility of modifiable and nonmodifiable factors. The analysis of non-modifiable factors may shed light on certain patient groups at high risk for a long DUI, whereas modifiable factors may be used more directly to derive recommendations for early intervention. In general, the majority of existing studies uses exclusively a qualitative approach and additional quantitative studies are urgently needed. ${ }^{19,20}$ Along with the new quantitative data, the FABIANA study may also stimulate further research by providing a new instrument for the combined assessment of multiple facilitators and barriers in anorexia nervosa treatment initiation.

\section{Limitations}

As a potential limitation, the applied retrospective assessment of the DUI needs to be discussed. However, a prospective design does not seem to be a viable option because of the comparably low prevalence rates of anorexia nervosa. ${ }^{2,3}$ Furthermore, the study will only include patients at the beginning of their first treatment. In order to minimise response shifts and recall biases, the maximum time passed between treatment initiation and study entry is limited to 3 months. ${ }^{48}$ Additionally, following existing recommendations, anchor points will be used to assess the onset of the eating disorder pathology. ${ }^{28}$ 
Another potential methodological limitation worth mentioning is the version of SCID used. At the time of the study conception and the beginning of recruitment the German version of the updated SCID for DSM-V diagnoses was not yet available. Therefore, we will use, for consistency reasons, the older version referring to DSM-IV diagnoses during all substudies primarily. ${ }^{1,49}$ After publication we will use the version for DSM-V diagnoses additionally. Compared with the update, the older SCID version contains slightly stricter criteria for anorexia nervosa (i.e. occurrence of an endocrine dysfunction, BMI criterion of $17.5 \mathrm{~kg} / \mathrm{m}^{2}$ ) and leads to slightly lower prevalence rates. ${ }^{50}$ This may be counterbalanced by the inclusion of patients with atypical anorexia nervosa, so that a marked effect on the selection of study patients may not be expected.

Furthermore, it is important to consider that the findings of the FABIANA study are not independent from the way the healthcare system in Germany functions. The national mental healthcare system is generally well developed and the costs of specialised psychotherapeutic treatments is fully covered by healthcare insurance for the vast majority of patients with anorexia nervosa. However, in contrast to other countries large-scale early-intervention models for people with anorexia nervosa are not implemented within routine care in Germany so far. ${ }^{15}$ The findings of the FABIANA study need to be discussed against this background.

Finally, it is important to point out that the FABIANA study focuses on the time until first psychotherapeutic treatment rather than on correlates of treatment-seeking. This means that the study population will only include individuals who eventually receive professional psychotherapeutic treatment. However, individuals without specialised health service utilisation constitute a large proportion of all those with diagnosable eating disorders. A systematic review estimated this proportion at $76.8 \%{ }^{51}$ Further studies on people with eating disorders but without mental health service utilisation are recommended and the findings of the FABIANA study should be interpreted in the light of this limitation.

In conclusion, the FABIANA study aims to generate new and more comprehensive insights into the process of anorexia nervosa treatment initiation from the perspectives of adolescent and adult patients as well as their key contacts. Moreover, a core target of the study is to develop an instrument to assess multiple key facilitators and barriers, which may be a valuable resource for further research efforts. In addition, the quantification of the effects of individual facilitators and barriers with consideration of their modifiability is an essential prerequisite to derive evidence-based recommendations for improved early intervention. Ultimately, the findings of the FABIANA study aim to contribute to the prevention of a chronic course of illness in patients with anorexia nervosa.

Denise Kästner (D), Postdoctoral Researcher, Department of Psychosomatic Medicine and Psychotherapy, University Medical Center Hamburg-Eppendorf, Germany; Ines Buchholz, Postdoctoral Researcher, Department of Psychosomatic Medicine and Psychotherapy, University Medical Center Hamburg-Eppendorf, Germany;

Angelika Weigel, Postdoctoral Researcher, Department of Psychosomatic Medicine and Psychotherapy, University Medical Center Hamburg-Eppendorf, Germany;

Romuald Brunner, Professor, Clinic and Policlinic of Child and Adolescent Psychiatry, Psychosomatic Medicine and Psychotherapy, University Clinic Regensburg, Germany; Ulrich Voderholzer, Professor, Schön Clinic Roseneck Prien; Department of Psychiatry and Psychotherapy, University Hospital Freiburg; and Department of Psychiatry and Psychotherapy, University of Munich, Germany; Antje Gumz, Professor, Department of Psychosomatic Medicine and Psychotherapy, University Medical Center HamburgEppendorf; and Berlin Psychological University, Germany; Bernd Löwe, Professor, Department of Psychosomatic Medicine and Psychotherapy, University Medical Center Hamburg-Eppendorf, Germany

Correspondence: Denise Kästner, Department of Psychosomatic Medicine and Psychotherapy, University Medical Center Hamburg-Eppendorf, Martinistr. 52, W37, 20246 Hamburg, Germany. Email: d.kaestner@uke.de

First received 24 Apr 2019, final revision 6 Aug 2019, accepted 19 Sep 2019

\section{Funding}

This study is funded by the German Research Foundation. Principal investigators are B.L. (LO 766/16-1, substudy I) and A.G. (GU 1564/3-1, substudy II \& III). The funding body is not involved in the study design, data collection, analysis and interpretation.

\section{Acknowledgements}

We would like to thank all of our cooperating partners who are or will be involved in the recruitment of study participants for the FABIANA study. Alphabetically ordered, these are: Asklepios menic Nord-Ochsenzoll (Hamburg), Asklepios Clinic West Hamburg (Hamburg), Clinic Lüneburger Heide (Bad Bevensen), Curtius Clinic (Bad Malente), Department of Child and Adolescent Psychiatry, University Clinic Regensburg (Regensburg), Department of Child and Adolescent Psychiatry, University Hospital Heidelberg (Heidelberg), Dipl.-Psych. B. MatzKnocke (Hamburg), Dipl.-Psych. M. Axhausen (Hamburg), Dipl.-Psych. S. la Roche (Hamburg), Institute for Behavior Therapy Training Hamburg (IVAH, Hamburg), Medical Care Center for Psychotherapy, Psychiatry and Psychosomatics Falkenried (Hamburg), Medical Care Center Timmermann and Partner (Cuxhaven), Mediclin Seepark Clinic (Bad Bodenteich), Psychosomatic Clinic of the Evangelic Hospital Ginsterhof (Rosengarten), Schön Clinic Bad Arolsen (Bad Arolsen), Schön Clinic Bad Bramstedt (Bad Bramstedt), schön Clinic Hamburg Eilbek (Hamburg), Schön Clinic Roseneck (Prien am Chiemsee), Specialist counseling centre for eating disorders - Waage e.V. (Hamburg), Training Center for Behavior Therapy Falkenried (NTFAW, Hamburg). Furthermore, we want to thank Dr Marco Lehmann and Dr Pascal Jordan for their statistical guidance and support during the conception of the study. 


\section{Appendix}

\begin{tabular}{|c|c|c|c|c|}
\hline & Patients & Therapist & Carers & Physicians \\
\hline Questionnaire & $\begin{array}{l}\text { Age, marital status, partnership, } \\
\text { children, siblings, education, } \\
\text { employment, migrant } \\
\text { background, urbanisation, health } \\
\text { insurance; for minor patients: } \\
\text { school, marital and educational } \\
\text { status of the parents } \\
\text { Current height and weight, lowest and } \\
\text { highest weight including dates, } \\
\text { rapid weight loss, lifetime } \\
\text { occurrence of anorexia nervosa } \\
\text { symptoms, life chart } \\
\text { Date of treatment initiation, date of } \\
\text { first anorexia nervosa diagnosis, } \\
\text { previous psychotherapy, internal } \\
\text { versus external motivation for } \\
\text { treatment initiation, family history } \\
\text { for anorexia nervosa } \\
\text { SCID-Il questionnaire }\end{array}$ & $\begin{array}{l}\text { Date of treatment } \\
\text { initiation } \\
\text { Weight, height and body } \\
\text { mass index at } \\
\text { treatment initiation } \\
\text { Number of comorbid } \\
\text { Axis I and Axis II } \\
\text { diagnoses }\end{array}$ & $\begin{array}{l}\text { Gender, year of birth } \\
\text { Relationship to the } \\
\text { patient, shared } \\
\text { living situation with } \\
\text { patient }\end{array}$ & $\begin{array}{l}\text { Gender, year of birth } \\
\text { Specialty, year of } \\
\text { approbation } \\
\text { Additional qualifications } \\
\text { regarding mental } \\
\text { disorders, experience } \\
\text { with patients with } \\
\text { mental disorders } \\
\text { Duration of treating the } \\
\text { study patient }\end{array}$ \\
\hline Interview & $\begin{array}{l}\text { Interview I: } \\
\text { Check of inclusion and exclusion } \\
\quad \text { criteria } \\
\text { Assessment of DUI } \\
\text { Facilitators and barriers } \\
\text { Interview II: } \\
\text { SCID-I and SCID-1II,26 }\end{array}$ & - & Facilitators and barriers & Facilitators and barriers \\
\hline
\end{tabular}

\section{References}

1 American Psychiatric Association. Diagnostic and Statistical Manual of Mental Disorders, DSM-V (5th edn). APA, 2013.

2 Keski-Rahkonen A, Mustelin L. Epidemiology of eating disorders in Europe: prevalence, incidence, comorbidity, course, consequences, and risk factors. Curr Opin Psychiatry 2016; 29: 340-5.

3 Smink FR, van Hoeken D, Hoek HW. Epidemiology, course, and outcome of eating disorders. Curr Opin Psychiatry 2013; 26: 543-8.

4 Hoang $U$, Goldacre M, James A. Mortality following hospital discharge with a diagnosis of eating disorder: national record linkage study, England, 20012009. Int J Eat Disord 2014; 47: 507-15.

5 Löwe B, Zipfel S, Buchholz C, Dupont Y, Reas D, Herzog W. Long-term outcome of anorexia nervosa in a prospective 21-year follow-up study. Psychol Med 2001; 31: 881-90

6 Zipfel S, Giel KE, Bulik CM, Hay P, Schmidt U. Anorexia nervosa: aetiology, assessment, and treatment. Lancet Psychiatry 2015; 2: 1099-111.

7 Weigel A, König HH, Gumz A, Löwe B, Brettschneider C. Correlates of health related quality of life in anorexia nervosa. Int J Eat Disord 2016; 49: 630-4.

8 Stuhldreher N, Wild B, Konig HH, Konnopka A, Zipfel S, Herzog W. Determinants of direct and indirect costs in anorexia nervosa. Int J Eat Disord 2015; 48: 139-46.

9 National Institute for Health and Care Excellence. Eating Disorders: Recognition and Treatment. National Institute for Health and Care Excellence: Clinical Guidelines. NICE, 2017

10 Berends T, Boonstra N, van Elburg A. Relapse in anorexia nervosa: a systematic review and meta-analysis. Curr Opin Psychiatry 2018; 31: 445-55.

11 Fichter MM, Quadflieg N, Crosby RD, Koch S. Long-term outcome of anorexia nervosa: results from a large clinical longitudinal study. Int J Eat Disord 2017; 50: 1018-30.

12 Zipfel S, Löwe B, Reas DL, Deter H-C, Herzog W. Long-term prognosis in anorexia nervosa: lessons from a 21-year follow-up study. Lancet 2000; 355: 721-2.

13 Steinhausen HC. The outcome of anorexia nervosa in the 20th century. Am J Psychiatry 2002; 159: 1284-93.

14 Dell'Osso B, Glick ID, Baldwin DS, Altamura AC. Can long-term outcomes be improved by shortening the duration of untreated illness in psychiatric disorders? A conceptual framework. Psychopathology 2013; 46: 14-21.
15 McGorry PD, Mei C. Early intervention in youth mental health: progress and future directions. Evid Based Ment Health 2018; 21: 182-4.

16 MacDonald K, Fainman-Adelman N, Anderson KK, Iyer SN. Pathways to mental health services for young people: a systematic review. Soc Psychiatry Psychiatr Epidemiol 2018; 53:1005-38.

17 Weigel A, Rossi M, Wendt $H$, Neubauer K, von Rad K, Daubmann A, et al. Duration of untreated illness and predictors of late treatment initiation in anorexia nervosa. J Public Health 2014; 22: 519-27.

18 Neubauer K, Weigel A, Daubmann A, Wendt H, Rossi M, Löwe B, et al. Paths to first treatment and duration of untreated illness in anorexia nervosa: are there differences according to age of onset? Eur Eat Disord Rev 2014; 22: 292-8.

19 Ali K, Farrer L, Fassnacht DB, Gulliver A, Bauer S, Griffiths KM. Perceived barriers and facilitators towards help-seeking for eating disorders: a systematic review. Int J Eat Disord 2017; 50: 9-21.

20 Regan $\mathrm{P}$, Cachelin FM, Minnick AM. Initial treatment seeking from professional health care providers for eating disorders: a review and synthesis of potential barriers to and facilitators of 'first contact'. Int J Eat Disord 2017; 50: 190-209.

21 Schmidt U, Treasure J. Anorexia nervosa: valued and visible. A cognitive-interpersonal maintenance model and its implications for research and practice. Br J Clin Psychol 2006; 45: 343-66.

22 Innes NT, Clough BA, Casey LM. Assessing treatment barriers in eating disorders: a systematic review. Eat Disord 2017; 25: 1-21.

23 Priebe S, Wright $D$. The provision of psychotherapy: an international comparison. J Public Ment Health 2006; 5: 12-22.

24 Eccles JS. The development of children ages 6 to 14. Future Child 1999; 9: 30-44.

25 Salbach-Andrae H, Burger A, Klinkowski N, Lenz K, Pfeiffer E, Fydrich T, et al. Diagnostik von Persönlichkeitsstörungen im Jugendalter nach SKID-II. [Diagnostic of personality disorders in adolescence according to SCID-II.] Z Kinder Jugendpsychiatr Psychother 2008; 36: 117-25.

26 Wittchen H-U, Zaudig M, Fydrich T. SKID. Strukturiertes klinisches Interview für DSM-IV. Achse I und II. Handanweisung. [SCID. Structured Clinical Interview for DSM-IV. Manual.] Hogrefe-Verlag, 1997.

27 Kjellsson G, Clarke P, Gerdtham UG. Forgetting to remember or remembering to forget: a study of the recall period length in health care survey questions. $J$ Health Econ 2014; 35: 34-46.

28 Anderluh M, Tchanturia K, Rabe-Hesketh S, Collier D, Treasure J. Lifetime course of eating disorders: design and validity testing of a new strategy to define the eating disorders phenotype. Psychol Med 2009; 39: 105-14. 
29 Neuhauser H, Schienkiewitz A, Schaffrath-Rosario A, Dortschy R, Kurth BM. Referenzperzentile für anthropometrische Maßzahlen und Blutdruck aus der Studie zur Gesundheit von Kindern und Jugendlichen in Deutschland (KiGGS). [Percentile reference values for anthropometric indices and blood pressure based on the German Health Interview and Examination Survey for Children and Adolescents.] Robert Koch-Institut, 2013.

30 Le Grange D, Doyle PM, Swanson SA, Ludwig K, Glunz C, Kreipe RE. Calculation of expected body weight in adolescents with eating disorders. Pediatrics 2012; 129: $\mathrm{e} 438-46$

31 Strauss A, Corbin J. Grounded Theory: Grundlagen qualitativer Sozialforschung. [Grounded Theory: Basics of Qualitative Social Research.] Psychologie Verlags Union, 1996.

32 Strübing J. Grounded Theory (2nd edn). VS Verlag, Wiesbaden, 2008.

33 Software V. MAXQDA. VERBI Software, 2018

34 Breuer F. Reflexive Grounded Theory: Eine Einführung in die Forschungspraxis (2nd edn). [Reflexive Grounded Theory: An Introduction to a Research Practice.] Wiesbaden: VS Verlag für Sozialwissenschaften. Springer Fachmedien, 2011.

35 Pentzek M, Wollny A, Herber OR, Porst R, Icks A, Abholz HH, et al Itemkonstruktion in sequentiellen Mixed-Methods-Studien: methodenbeschreibung anhand eines Beispielprojekts. [Item construction in sequential mixed methods studies: Description of an approach.] Zeitschrift für Allgemeinmedizin 2012; 88: 520-7.

36 Tabachnik BG, Fidell LS. Using Multivariate Statistics (3rd edn). Harper Collins, 1996.

37 Moosbrugger $\mathrm{H}$, Kelava A. Testtheorie und Fragebogenkonstruktion. [Test Theory and Questionnaire Construction.] Springer, 2012.

38 Kliem S, Mossle T, Zenger M, Strauss B, Brahler E, Hilbert A. The Eating Disorder Examination-Questionnaire 8: a brief measure of eating disorder psychopathology (EDE-Q8). Int J Eat Disord 2016; 49: 613-6.

39 Kliem S, Schmidt R, Vogel M, Hiemisch A, Kiess W, Hilbert A. An 8-item short form of the Eating Disorder Examination-Questionnaire adapted for children (ChEDE-Q8). Int J Eat Disord 2017; 50: 679-86.

40 Babitsch B, Gohl D, von Lengerke T. Re-revisiting Andersen's Behavioral Model of Health Services Use: a systematic review of studies from 1998-2011. Psychosoc Med 2012; 9, Doc11.

41 Schlegl S, Hupe K, Hessler JB, Diedrich A, Huber T, Rauh E, et al. Wege in die Versorgung und Behandlungslatenzen bei stationären Patienten mit Anorexia und Bulimia nervosa. [Pathways to care and duration of untreated illness of inpatients with anorexia and bulimia nervosa.] Psychiatr Prax 2019; 46(06): 342-348.

42 Collins GS, Reitsma JB, Altman DG, Moons KG. Transparent reporting of a multivariable prediction model for individual prognosis or diagnosis (TRIPOD): the TRIPOD Statement. BMC Med 2015; 162: 55-63.

43 Tong $A$, Sainsbury $P$, Craig J. Consolidated criteria for reporting qualitative research (COREQ): a 32-item checklist for interviews and focus groups. Int $J$ Qual Health Care 2007; 19: 349-57.

44 von Elm E, Altman DG, Egger M, Pocock SJ, Gotzsche PC, Vandenbroucke JP, et al. The Strengthening the Reporting of Observational Studies in Epidemiology (STROBE) statement: guidelines for reporting observational studies. Lancet 2007; 370: 1453-7.

45 Brown A, Mcclelland J, Boysen E, Mountford V, Glennon D, Schmidt U. The FREED Project (first episode and rapid early intervention in eating disorders): service model, feasibility and acceptability. Early Interv Psychiatry 2018; 12 $250-7$

46 Nicholls $D E$, Yi I. Early intervention in eating disorders: a parent group approach. Early Interv Psychiatry 2012; 6: 357-67.

47 Thorpe C, Ryan B, McLean SL, Burt A, Stewart M, Brown JB, et al. How to obtain excellent response rates when surveying physicians. Fam Pract 2009; 26: 65-8.

48 Blome C, Augustin M. Measuring change in quality of life: bias in prospective and retrospective evaluation. Value Health 2015; 18: 110-5.

49. World Health Organization. International Statistical Classification of Diseases and Related Health Problems (11th Revision). WHO 2018 (https://icd.who.int/ browse11/l-m/en).

50 Ernst V, Bürger A, Hammerle F. Prevalence and severity of eating disorders: a comparison of DSM-IV and DSM-5 among German adolescents. Int J Eat Disord 2017; 50: 1255-63

51 Hart LM, Granillo MT, Jorm AF, Paxton SJ. Unmet need for treatment in the eating disorders: a systematic review of eating disorder specific treatment seeking among community cases. Clin Psychol Rev 2011; 31: 727-35. 